reasonable to assume that Paget's disease was a major contributing factor to deafness in most of these cases.

Audiological assessment was confined to a clinical examination, and pure-tone and impedance audiometry. Tone decay and tests for recruitment and speech audiometry were not included because they do not clarify the diagnosis and they would have been confusing and tiring for a group of elderly patients. Temporal bone tomography was not undertaken because of the risks to the eye.

With these tests we have observed a trend for the conductive component and to a lesser degree the high-frequency sensorineural component of deafness to deteriorate less rapidly in patients on continuous calcitonin treatment than in untreated patients. Intermittently treated patients showed intermediate changes. The observations in case 7 suggest that hearing loss may be delayed though not actually prevented by effective calcitonin treatment.

Previous reports of the effect of calcitonin on deafness have shown conflicting results. Shai et al ${ }^{\times}$reported an improvement in air conduction at low frequencies in three out of six patients treated with porcine calcitonin for six to 17 weeks. Moffat et al ${ }^{9}$ reported a single case of improvement after 23 weeks' porcine calcitonin treatment. Neither of these studies included a control group and the patient described by Moffat et al had no evidence of Paget's disease in the skull. Grimaldi et al ${ }^{10}$ failed to show any change in the hearing of their patients who were treated with salmon or human calcitonin for 12 to 62 weeks, nor could Menzies et al ${ }^{11}$ show any improvement in the hearing of four patients treated with human calcitonin 1011 after 18-22 months.

In general the severity of deafness in Paget's disease is related to the extent of the bony disease, and most suggested mechanisms are related to the abnormal bone architecture. If long-term calcitonin treatment is effective in arresting the disease process or even in restoring bone structure to a more normal state then some benefit to hearing might be expected to occur, and our results suggest that this may indeed be so. Nevertheless, the number of patients, the period of observation, and the size of the changes are small. On the available evidence, deafness should not be regarded as an indication for calcitonin therapy in Paget's disease, but our findings suggest that further moreprolonged studies are needed.

We thank Mr L O'Neill who performed the audiograms and the department of medical illustration, University Hospital of South Manchester.

\section{References}

${ }^{1}$ Nager, G T, Annals of Otology, Rhinology and Laryngology, 1975, 84, suppl 22, No 4, part 3.

2 Davies, D G, Acta Oto-laryngologica, 1968, suppl No 242.

${ }^{3}$ Lindsay, J R, and Perlman, H B, Archives of Otolaryngology, 1936, 23, 580.

Waltner, J G, Archives of Otolaryngology, 1965, 82, 355

${ }^{5}$ DeRose, J, et al, American fournal of Medicine, 1974, 56, 858.

${ }^{6}$ Melick, R A, Ebeling, P, and Hjorth, R J, British Medical fournal, 1976, $1,627$.

${ }^{7}$ Haddad, J G, and Caldwell, J G, Fournal of Clinical Investigation, 1972, 51, 3133.

${ }^{8}$ Shai, F S, Baker, R K, and Wallach, S, fournal of Clinical Investigation, 1971, 50, 1927.

${ }^{9}$ Moffat, W H, Morrow, J D, and Simpson, N, British Medical fournal, $1974,4,203$.

10 Grimaldi, P M G B, Mohamedally, S M, and Woodhouse, N J Y, British Medical fournal, 1975, 2, 726 .

1 Menzies, M A, Greenberg, P B, and Joplin, G F, Acta Oto-laryngologica, $1975,79,378$.

\title{
Acceptability of an oral contraceptive that reduces the frequency of menstruation: the tri-cycle pill regimen
}

\author{
N B LOUDON, M FOXWELL, D M POTTS, A L GUILD, R V SHORT
}

British Medical fournal, 1977, 2, 487-490

\section{Summary}

The frequency of menstruation was reduced to once every three months in 196 women by the continuous administration of the oral contraceptive pill, Minilyn, for 84 days (tri-cycle regimen). No pregnancies occurred. One hundred and sixty-one women $(82 \%)$ welcomed the reduction in the number of periods with the as-

Family Planning Services, Lothian Health Board, Edinburgh

N B L.OUDON, MB, CHB, medical co-ordinator

M FOXWELL, SRN, nursing sister

International Pregnancy Advisory Services, Chapel Hill, North Carolina 27514, USA

D M POTTS, MB, PHD, director

Medical Research Council, Unit of Reproductive Biology, Edinburgh EH1 2QW

A L GUILD, MA, research technician

R V SHORT, SCD, FRS, director sociated freedom from menstrual and premenstrual symptoms, and many found the tri-cycle regimen easier to follow. Weight gain of more than $2 \mathrm{~kg}$, irregular cycle control, especially in the first three months, breast tenderness, and headaches were the main side effects. Menstrual loss was unchanged or reduced in all but seven women. The doctors and nurses on the clinic staff were less enthusiastic about this regimen than the volunteers themselves.

\section{Introduction}

When Dr Gregory Pincus first developed the oral contraceptive pill in the late 1950s he proposed a dosage regimen that would induce withdrawal bleeding every 28 days. Although the length of the cycle while on the pill is purely arbitrary, Pincus tried to imitate as closely as possible the length of the normal menstrual cycle to make the pill more acceptable when oral contraception was still a novel concept.

Since then the ability of synthetic ovarian hormones to control ovulation has been widely exploited, and it is now estimated that over 50 million women use the pill ${ }^{1}$; probably as many again have used it at some time. The pill has proved 
successful not only in developed but also in developing countries, such as Thailand, Colombia, and the People's Republic of China. Nevertheless, the ability of the pill to control the pattern of uterine bleeding has not been exploited. There is no evidence to suggest that the normal menstrual cycle represents some inherent rhythm of the central nervous system which it would be harmful to disrupt. On the contrary, a succession of menstrual cycles is a relatively recent consequence of late marriage and family limitation-in pre-literate communities without access to contraception most of a woman's reproductive life was occupied by long periods of lactational amenorrhoea interspersed with five or six pregnancies. ${ }^{2}$

There are various reasons why restricting the number of menstrual cycles might prove beneficial. Apart from reducing menstrual blood loss and adverse menstrual symptoms, less frequent exposure of the breasts and the endometrium to monthly hormonal fluctuations might even reduce the long-term incidence of disease in these organs. ${ }^{3}$

We describe the results of a trial designed to assess the acceptability of a reduction in the frequency of menstruation to once every three months (tri-cycle pill regimen).

\section{Subjects and methods}

Two hundred and two women, aged between 18 and 45 years, married and unmarried, were recruited from the normal attenders at the Edinburgh Family Planning Centre. They were recruited over a period of three months from among a total of 3439 women attending the centre during that time. Of the 196 women followed up, $182(93 \%)$ were already established pill-takers, $108(55 \%)$ of them already using Minilyn (Organon; lynoestrenol $2.5 \mathrm{mg}$, ethinyloestradiol $0.05 \mathrm{mg}$ ), on which another trial was being conducted at the time in the centre.

Many women volunteered in response to a notice in the waiting room about the tri-cycle pill trial. The clinic staff also offered the new regimen to suitable patients; press publicity attracted a few more volunteers. The normal criteria for prescription of oral contraceptives were applied, and standard clinic procedures and follow-up routines were adopted. Each patient was issued with a clear written explanation of the trial, and similar details were sent to her general practitioner.

Permission was obtained from the Committee on Safety of Medicines to use Minilyn for the tri-cycle pill trial. This pill was taken for 84 days followed by 6 pill-free days to allow for withdrawal bleeding. Patients who were not already taking oral contraceptives began the tri-cycle regimen on the first day of menstruation, and contraceptive cover was considered to be effective immediately. Patients who transferred from the normal pill-taking regimen did so after the standard interval of six or seven pill-free days. Additional contraceptive precautions were recommended for the first 14 days after the changeover. The tri-cycle regimen was continued for one year, giving four withdrawal bleeds at three-monthly intervals.

Each woman kept a diary card to record tablet-taking, uterine bleeding, and any side effects she chose to specify. After completing 12 months on the tri-cycle pill, or after premature withdrawal from the trial, each woman was invited to complete a simple written questionnaire. The first two questions invited the woman's free comments on general likes and dislikes about the tri-cycle regimen. These were followed by four specific questions on whether or not she had been concerned about the risk of pregnancy; the possibility that her periods might not return; whether the regimen was "interfering with nature" in a way that was not fully understood; and whether she would feel happier with monthly cycles because they were more "natural."

Women who failed to keep their clinic appointments were followed up by letter or by home visit. Permission to follow up in this way had been obtained at enrolment.

\section{Results}

The age distribution, marital state, and social class of the volunteers appeared to reflect the general clinic population, and was biased towards social classes I, II, and III. Of the 202 women who enrolled in the trial, six were lost to follow-up within the first three months, submitting no data, and not completing the questionnaire. One hundred and seven women completed the whole 12 months, and 89 withdrew (table I). Fourteen of the women who withdrew did so either to plan a pregnancy, for sterilisation, or because contraception was no longer required (table II). Of the nine women who stopped to plan a pregnancy, six are known to have conceived within nine months, while two were still not pregnant after 10 and 11 months, and one was lost to follow-up. The two who failed to become pregnant had used Minilyn tri-cyclically for six and three months respectively. An appointment was made for one patient to attend the endocrine clinic, but she failed to attend, and subsequently left the area. The other was referred to the infertility clinic and her husband was being investigated for Klinefelter's syndrome.

TABLE I-Numbers of women who participated in the tri-cycle pill trial, and those who later withdrew

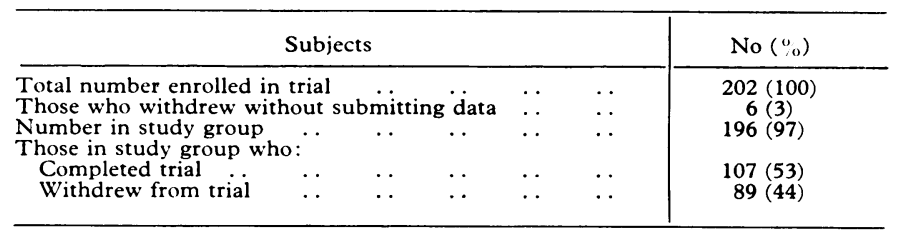

TABLE $\mathrm{I}$-Reasons given by 89 zomen for withdrazing from trial

\begin{tabular}{|c|c|c|c|c|c|}
\hline \multicolumn{5}{|c|}{ Reason } & \multirow[b]{2}{*}{$\begin{array}{c}\text { No }\left({ }^{\prime \prime} .\right) \text { of women } \\
9(10) \\
3(3.5) \\
2(2) \\
11(12) \\
10(11) \\
5(6) \\
6(7) \\
5(6) \\
5(6) \\
33(36.5)\end{array}$} \\
\hline $\begin{array}{l}\text { To plan pregnanc } \\
\text { To be sterilised } \\
\text { Contraception no } \\
\text { Weight gain ... } \\
\text { Spotting or breakt } \\
\text { Headaches .. } \\
\text { Dysmenorrhoea } \\
\text { Breast discomfort } \\
\text { Depression ... } \\
\text { Other* }\end{array}$ & $\begin{array}{cc}\ldots & \ldots \\
\text { onger needed } & \\
\text {. } & \\
\text { arough bleedin } \\
\ldots & \ldots \\
\ldots & \cdots \\
\ldots & \cdots \\
\ldots & \ldots\end{array}$ & $\begin{array}{lr}. & \ldots \\
\cdots & \cdots \\
\therefore & \cdots \\
\text { g, or both } \\
\cdots & \cdots \\
\cdots & \cdots \\
\cdots & \cdots \\
\cdots & \cdots\end{array}$ & $\begin{array}{l}\ldots \\
\ldots \\
\cdots \\
\cdots \\
\cdots \\
\cdots \\
\cdots\end{array}$ & $\begin{array}{l}\ldots \\
\because \\
\because \\
\because \\
\because \\
\because \\
\because \\
\cdots\end{array}$ & \\
\hline
\end{tabular}

*Includes vaginal discharge, spots, constipation, loss of libido, nausea.

\section{SIDE EFFECTS}

Cycle control was fairly good, as the incidence of both spotting and breakthrough bleeding diminished in each successive three-monthly cycle (see table III). Seventeen $(8.5 \%$ ) of the 196 women developed breakthrough bleeding, but only two of them had episodes of bleeding lasting longer than five days in any three-monthly cycle. Six reported breakthrough bleeding when they had missed tablets. Of the 11 women who reported breakthrough bleeding not associated with missed tablets, six $(3 \%)$ experienced this in the first three-month period, four $(3 \%)$ in the second three months, one $(1 \%)$ in the third three months, and nobody had breakthrough bleeding after using the regimen for nine months.

Forty-seven women $(24 \%)$ complained of spotting in the first cycle, while, of those who continued, only $21(16 \%)$ complained of spotting in the second, $11(10 \%)$ in the third, and four $(4 \%)$ in the fourth cycle. Among the 47 women who had spotting in the first threemonthly cycle, in $16(34 \%)$ it lasted for less than six days, and in over half of these episodes spotting followed one or more missed tablets.

Withdrawal bleeding failed to occur only once during the six pillfree days. There was no delay in onset of withdrawal bleeding compared with the standard 28-day oral contraceptive regimen. Although blood loss was not measured, only seven women reported that their periods were heavier than normal, while all the others reported them as unchanged or even diminished. Eighteen women $(9 \%)$ complained of dysmenorrhoea but $39(20 \%)$ reported fewer unpleasant symptoms associated with menstruation. Ninety women $(46 \%)$ reported wieght gain of more than $2 \mathrm{~kg}$. Twenty-two $(11 \%$ ) reported increased incidence of headaches.

TABLE III-Percentage incidence of spotting and breakthrough bleeding during four successive three-monthly cycles. Results expressed as proportions of women who were still participating in the study

\begin{tabular}{c|c|c}
\hline Three-monthly cycle & Spotting & Breakthrough bleeding \\
\hline 1 & $47 / 196(24 \%)$ & $6 / 196\left(3^{\circ} \%\right)$ \\
2 & $21 / 133(16 \%)$ & $4 / 133\left(3^{\circ} \%\right)$ \\
3 & $11 / 110(10 \%)$ & $1 / 110(1 \%)$ \\
$4 / 107(4 \%)$ & $0 / 107$ \\
\hline
\end{tabular}


Breast discomfort reported by 26 women (13\%) appeared to become less troublesome as the trial progressed. One woman reported galactorrhoea, but when she was examined six days later no milk or fluid could be expressed from the breast, and the condition did not recur. A fibroadenoma was excised from the breasts of two women. In one case it was detected within three months of starting the tri-cycle regimen and in the other during the fourth three-monthly cycle. One woman developed an ovarian cyst during the second month of the trial.

\section{WITHDRAWALS}

Among the 89 women who withdrew from the trial three failed to complete one month, six withdrew after two months, and the largest single group of 32 withdrew at the end of the first three months. There was no significant relationship between withdrawal and parity or marital state (see table IV). Thirty-three $(36.5 \%$ ) of those who withdrew from the study did so because of various side effects allegedly caused by the regimen-vaginal discharge, "spotty" face, constipation, loss of libido, nausea, etc.

The main medical reasons for withdrawing were excessive weight gain, spotting or breakthrough bleeding, increased dysmenorrhoea, headaches, breast discomfort, and depression (see table II). But even among this group, $59(66 \%)$ liked the idea of less frequent periods, and only two women withdrew because they were primarily unhappy with infrequent periods. Most of these women $(65 ; 73 \%$ ), however, reverted to conventional monthly oral contraceptive treatment on withdrawal from the study (table V).

TABLE IV-Relation between whether or not women withdrew from the trial and their marital state and parity. Figures are numbers of subjects

\begin{tabular}{|c|c|c|c|}
\hline & Continued & Withdrew & Total \\
\hline $\begin{array}{l}\text { Marital state*: } \\
\text { Married } \\
\text { Single } \\
\text { Divorced }\end{array}$ & $\begin{array}{l}74 \\
33\end{array}$ & $\begin{array}{r}67 \\
21 \\
1\end{array}$ & $\begin{array}{r}141 \\
54 \\
1\end{array}$ \\
\hline Total & 107 & 89 & 196 \\
\hline $\begin{array}{l}\text { Parity (No of births) } \dagger: \\
0 \\
1 \\
2 \\
3 \\
4\end{array}$ & $\begin{array}{r}67 \\
10 \\
25 \\
4 \\
1\end{array}$ & $\begin{array}{r}59 \\
9 \\
14 \\
7\end{array}$ & $\begin{array}{r}126 \\
19 \\
39 \\
11 \\
1\end{array}$ \\
\hline Total & 107 & 89 & 196 \\
\hline
\end{tabular}

$\chi^{2}=2 \cdot 18 ; \mathrm{DF}=2 ;$ not significant.

$\begin{aligned} \chi^{2} & =2 \cdot 18 ; \mathrm{DF}=2 ; \text { not significant. } \\ \chi^{2} & =4 \cdot 3 ; \mathrm{DF}=4 ; \text { not significant. }\end{aligned}$

TABLE $\mathrm{v}-$ Methods of contraception subsequently adopted by the 89 women who withdrew from the trial

\begin{tabular}{|c|c|c|c|c|c|c|}
\hline \multicolumn{6}{|c|}{ Method } & \multirow{2}{*}{$\frac{\text { No }\left({ }^{0} \mathrm{o}\right) \text { of women }}{65(73)}$} \\
\hline Monthly oral contrace & e.. & . & .. & . & . & \\
\hline Sheath & .. & . & .. & .. & .. & $5(6)$ \\
\hline Intrauterine device. & .. & . & .. & .. & .. & $1(1)$ \\
\hline $\begin{array}{lll}\text { Diaphragm } & \ldots & \ldots\end{array}$ & .. & .. & .. & . & .. & $3(3.5)$ \\
\hline Sterilisation .. & .. & .. & .. & .. & .. & $3(3.5)$ \\
\hline None & .. & . & .. & .. & .. & $12(13)$ \\
\hline
\end{tabular}

\section{PERCEPTIONS OF PATIENTS}

All women were given a questionnaire regardless of whether they successfully completed the trial or withdrew. In response to the two open-ended questions women gave a number of reasons for liking the regimen. These included infrequent periods $(161 ; 82 \%)$, fewer menstrual problems $(39 ; 20 \%$ ), and easier pill-taking regimen $(37 ; 19 \%)$. The dislikes included weight gain $(33 ; 17 \%)$ and headaches $(16 ; 8 \%$ ). Some women commented on change of libido (six $(3 \%)$ reported a decline), but the relevance of this was difficult to assess. In response to four specific questions some women, even though giving overall approval to the regimen, had reservations about certain aspects of it. Forty-five $(23 \%)$ were concerned by the lack of the monthly menstrual reassurance that they were not pregnant, but this doubt diminished with successive three-monthly cycles. Sixteen $(8 \%)$ worried that their periods might not return when they stopped the tri-cycle regimen, and $51(26 \%)$ were genuinely worried that they were interfering with nature in a way which they did not understand. Thirty-seven ( $19 \%$ ) admitted at the end of their participation in the trial that they were happier with monthly cycles, but even among those who discontinued the trial for one reason or another, $41(46 \%)$ said that they would be willing to try the tri-cycle regimen at a future date using a lower dose pill. At the end of the trial, all those still taking part were asked to revert to the standard monthly oral contraceptive regimen; $97(91 \%)$ refused to do this, preferring to continue with tri-cycle Minilyn. Sixteen $(15 \%$ ) even declined an offer to transfer to a tri-cycle pill containing a lower dose of oestrogen.

\section{PERCEPTIONS OF CLINIC STAFF}

All the doctors and nurses working in the family planning centre took part in running this trial. On completion of the trial the 24 doctors and 9 nurses were asked to complete a questionnaire. Seventeen $(52 \%)$ of the staff approved to the idea of reduction in number of periods, and $14(42 \%)$ were impressed by the diminution in adverse menstrual symptoms reported by patients. Seven $(21 \%)$ found that the tri-cycle pill regimen was easier for patients to follow, and $\operatorname{six}(18 \%)$ stated that the reduction in cost to the patient of sanitary protection was an important consideration.

Nevertheless, $13(39 \%)$ were concerned that patients might become pregnant without the medical adviser knowing about it, although a doctor resorted to a pregnancy test only once to allay this fear. Seven $(21 \%)$ were worried by weight increase, and six $(18 \%)$ considered irregular vaginal bleeding to be a source of concern. Four $(12 \%)$ were disturbed by increased breast tenderness, and four $(12 \%)$ also disapproved of manipulation of the menstrual cycle to reduce the number of periods. Ten (30\%) expressed concern lest regular monthly menstruation could not be re-established when tri-cycle pill treatment was discontinued.

Half of the doctors preferred to prescribe the pill according to the routine monthly regimen. Only one member of staff, a nurse, was unwilling to participate in another trial using a lower dose of oestrogen in a tri-cycle pill.

\section{Discussion}

This study shows unequivocally that many of the women who volunteered to take part in this trial liked using a contraceptive that also reduced the frequency of their menstrual periods. Cycle control was fairly good, and side effects, apart from weight gain and breast problems, were no commoner than those experienced on conventional oral contraceptive treatment. Our group of volunteers was not a random crosssection of the UK population, and it would be interesting to know how acceptable this regimen would be if made more widely available. Moreover, the clinic doctors and nurses were less enthusiastic than the participants about the advantages of reducing the number of menstrual periods.

A World Health Organisation survey of knowledgeable sources in 10 countries showed that "the unexpected presence or absence of vaginal bleeding, or variations in its characteristics, is alarming to women and perceived as a symptom of abnormality." "There is evidence, however, from several other sources that women would welcome the opportunity to manipulate their menstrual patterns. Conventional oral contraceptives have often been used to delay menstruation for social reasons, for example-marriage, examinations, competitive sport-and continuous lynoestrenol treatment has been used in the management of the mentally retarded. ${ }^{5}$ Miller and Smith ${ }^{6}$ interviewed a random cross-section of 88 unmarried, White, 18-23 year-old Californian girls, over half of whom were leading an active sex life, and found that $80^{\circ}$ o of them favoured the concept of eliminating menstruation. Clinical trials with long-acting injectable contraceptives that induce long-term amenorrhoea $\left(40^{\circ}\right.$ of women have amenorrhoea after three injections) have sometimes proved popular for this very reason.'

There are also cultural reasons why women in developing countries might welcome the opportunity to regulate menstrua- 
tion. It is considered unclean by some Hindu women to prepare their husband's food during menstruation; a Moslem woman cannot pray in the mosque when menstruating - a particularly burdensome restraint during the annual feast of Ramadan. A preliminary trial of a "Ramadan pill" in Calcutta in 1976 showed that the concept was understood by poor urban women. ${ }^{8}$ A few Moslem women already use hormonal treatment to postpone the menses when on pilgrimage to Mecca. Some Buddhists think it is wrong to enter a temple during menstruation. Possibly some of the emerging middle classes of the Third World countries might like to change their menstrual patterns for reasons of social convenience as in the West; the cost of sanitary protection is relatively a much greater burden for a woman with limited income. Perhaps other social groups would also like to avail themselves of this opportunity on specific occasions.

Having established that infrequent periods are welcome and attainable, we must now define the optimal dosage of steroids necessary to maintain symptom-free cycles, and establish the most acceptable cycle length. The present tri-cycle regimen is certainly not the final solution to this problem. In view of the acceptable cycle control achieved with a combined pill containing $50 \mu \mathrm{g}$ ethinyloestradiol we have already started a new trial using a pill with only $30 \mu \mathrm{g}$ of this oestrogen. Possibly the oestrogen dosage may even be further reduced in the latter weeks of each three-monthly cycle without sacrificing good cycle control.

These developments are part of the inevitable pattern of evolution of hormonal contraception, but any change in dosage regimen will require its own careful epidemiological assessment. If reduction of menstruation proves to be generally acceptable, it opens up a whole range of new and hitherto unexplored approaches to contraceptive development.

We thank R D Slacke of Organon Laboratories Ltd for preparing the special packs of pills and printing the instructions for this trial, and the staff of the Family Planning Centre for their help.

\section{References}

1 Piotrow, P T, and Lee, C M, Oral Contraceptives Population Report, Series A, Number 1. Washington, Publications of the Population Information Program, Dept of Medical and Public Affairs, The George Washington University Medical Centre, April 1974.

2 Short, R V, Proceedings of the Royal Society. Series B. Biological Sciences, 1976, 195, 3.

${ }^{3}$ Short, R V, in Physiology and Genetics of Reproduction, part A, ed E M Coutinho and F Fuchs. New York, Plenum Publishing Corporation, 1974.

4 World Health Organisation, Expanded Programme of Research, Development and Research Training in Human Reproduction. Fourth Annual Report. Geneva, WHO, 1975.

5 Lydecken, K, Acta Prychiatrica Scandinavica, 1972, suppl No 229.

${ }^{6}$ Miller, W B, and Smith, P J, Fournal of Psychiatric Research, 1975, 12 (3), 153.

${ }^{7}$ Koetsawang, S, et al, fournal of the Medical Association of Thailand, 1974, 57 (8), 396

${ }^{8}$ Mullick, B, 1977. Personal communication.

(Accepted 23 fune 1977)

\title{
Primary immunisation and febrile convulsions in Oxford 1972-5
}

\author{
PAUL HARKER
}

British Medical fournal, 1977, 2, 490-493

\section{Summary}

A three-year study of febrile convulsions in Oxford with comprehensive notification from general practice and hospitals showed a $3 \%$ risk for all children of suffering at least one febrile convulsion by the age of 5 years. Children were most at risk between 6 and 27 months, and febrile convulsions were most likely to be prolonged in children aged 9-15 months.

The association between febrile convulsions and primary immunisations in the preceding 28 days was compared in case and control children, matched for age and sex. Results suggested that such association was a chance relationship with age. If association was direct, the febrile convulsion rates per 1000 immunisation doses were estimated as follows: diphtheria, pertussis, tetanus -0.09 per 1000; poliomyelitis -0.6 per 1000 ; and measles -0.9 per 1000 . Hence if any of these vaccines had a specific causal relationship with febrile convulsions, these rates would probably have been much higher.

Oxford Area Health Authority (Teaching), Oxford OX1 1LE PAUL HARKER, MB, MFCM, community physician (child health)

\section{Introduction}

Prospective studies of birth cohorts have shown that $2-4 \%$ of children experience at least one febrile convulsion before 7 years of age. ${ }^{12}$ Epilepsy may develop in $2 \%$ of children who have had febrile convulsions. ${ }^{2}$ A causal link between prolonged febrile convulsions and epilepsy has been postulated. ${ }^{3}$ Febrile convulsions occur most commonly between the ages of 6 months and 3 years. Primary immunisation of children takes place during this period and at least two types of immunisationspertussis and measles-may potentially be accompanied by febrile and neurotoxic side effects. Surprisingly little is known about the association of primary immunisation with febrile convulsions.

In Millichap's book on febrile convulsions ${ }^{4}$ a review of studies suggests an association with immunisation in $0.7 \%$ of episodes, with a range from $1-4 \%$ in seven of 33 studies in which an association with immunisation was reported. These studies were of different type in different parts of the world between 1929 and 1964, and so a combined rate is relatively meaningless. None of the studies were from the United Kingdom. Landrigan and Witte ${ }^{j}$ summarised nine years' experience of measles immunisation in the United States. Eleven children in a population for whom 50.9 million doses of vaccine were distributed suffered febrile convulsions 5-15 days after immunisation-an incidence of $0 \cdot 2$ per million doses.

Pertussis immunisation has not been linked specifically with febrile convulsions. Kulenkempff et $a l^{6}$ reported neurological complications after pertussis immunisation in 36 